\title{
Histological And Ultrastructural Study On The Meibomian Gland Of Camel (Camelus dromedarius)
}

\author{
Balah AM, Abd EI-Raheem WA, El-Baz AM and Nesma I El-naseery \\ Histology and Cytology Department, Faculty of Veterinary Medicine, Zagazig University, Zagazig, Egypt
}

\begin{abstract}
The health and integrity of the ocular surface is dependent mainly on the meibomian glands (MGs). The MGs are lipid producing holocrine glands embedded within the tarsal plate of both the upper and lower eyelids in most animals. It is well known that the camel's eyelids are devoid of MGs. Our goals of this study is to reveal the existence of MGs in the mature male camel and try to describe its structural and ultrastructural features and correlate the obtained data with its function. The present study was conducted on $10 \mathrm{MGs}$ of mature male camels. The MGs were characterized, fixed, processed and $5 \mu \mathrm{m}$ paraffin sections were prepared and stained with different stains. Other MGs of $1 \mathrm{~mm}^{3}$ thick were fixed by Glutaraldehyde and processed for transmission electron microscope. Ultrathin sections were cut and stained with uranyl acetate and lead citrate. Macroscopically, it was an extrapalpebral gland and located in the inferior aspect of the eye with fine hairs on the palpebra tertia surface. Histologically, the MG was simple branched multilobular acinar glands that was surrounded by dense collagenous connective tissue (C.T.)..They were lined with multiple layers lipid-laden foamy meibocytes.Ultrastructurally, four types of acinar cells were observed: basal cells, moderately differentiated, fully-differentiated and degenerated meibocytes. The nuclei were flat in basal cells, discoid in moderately differentiated meibocytes, partially indented from one side by meibomian secretory vesicles(SVs) in fully-differentiated meibocytes and irregular outline with obvious indentation then fragmented in degenerated meibocytes. The moderately differentiated meibocytes were characterized by many electron dense mitochondria, and various forms of smooth endoplasmic reticulum (sER) which appeared as either grid lattice or parallel cisternae.
\end{abstract}

Conclusion: The mature male camel has MGs. It was an extrapalpebral gland and located in the inferior aspect of the eye. It was a large sebaecous gland. The structural characteristics of MGs might reflect their important physiological role in the tear film secretion and maintenance of healthy and integral ocular surface.

Key Words: meibomian glands, camel, ultrastructural,meibocytes.

Abbreviation

$\begin{array}{ll}\text { Ab } & \text { Alcian blue } \\ \text { C.T. } & \text { connective tissue } \\ \text { MG } & \text { meibomian gland } \\ \text { MGs } & \text { meibomian glands } \\ \text { rER } & \text { rough endoplasmic reticulum } \\ \text { SER } & \text { smooth endoplasmic reticulum } \\ \text { SVs } & \text { secretory vesicles }\end{array}$

\section{INTRODUCTION}

The MGs are well developed as regular arrays of parallel glands in the tarsal plates of the most mammals eyelids (1), as human (2-5); rabbits $(2,6)$, cats, goats, sheep, cattle (6), primates, steer (2), adult male albino rat (7); mouse(8), guinea pig (9) and chinchillas (10). The sea lions are lacking a distinct tarsus in the eyelids (11) and Turtles in their lower eyelid 
(12). The lemmings have only a few glands in the lid, supplemented by other extraorbital glands (13). However, it is well known that the MGs are absent in both eyelids of the camel (14-16), Snakes, lacertids and most sea mammals such as seals and cetaceans (1). It is a series of modified sebaceous glands in cat, rabbits, goats, sheep and cattle (6), rat (17), bats (18), human $(5,19,20)$. It is responsible for secretion of the outer lipid (oil) layer of the precorneal tear film $(21-23)$. The $\mathrm{MG}$ is consisted of numerous branched acini, each acinus is consisted of a basal layer of flattened cells and a mass of rounded cells with vacuolated cytoplasm in the adult male albino rat (7). There are two separate types of cells : undifferentiated basal cells and well differentiated cells of various sizes. The latter have rounded vesicular nuclei in the calf (24). Three types of cells in MGs acini basal, differentiating and degenerating are encountered in rabbit, primate (2) and human (25). Its oily secretion spreads as a surfactant over the globe and contributes as an aqueous barrier that remains functional after blinking (26) and maintains the vertical column of tears between the upper and lower lids (20). The secretion reduces evaporation by adding a hydrophobic layer to the surface of the tear film $(3,19,27)$, preventing dryness and maceration of the skin of the lid margin by tears (1), preventing the tears overflowing to on the lids and ensure their passage towards the lacus lacrimalis and the puncta (28), preventing contamination of the tear film by sebum through forming a barrier $(3,29)$, decreasing the surface tension of the tear film, thus preventing break up (3), preventing an overflow of tears along the palpebral rim $(3,30)$, sealing the lid margins during prolonged closure, providing a barrier against foreign particles, providing some anti-microbial activity (31) and providing of a smooth surface for refraction of incoming light rays (29) which enhances the protective properties of tear film.

The purpose of this study was to reveal the existence of MGs in the mature male camel and try to describe its structural and ultrastructural features and correlate the obtained data with its function.

\section{MATERIAL AND METHODS}

\section{Samples}

Ten eyelids and their adnexa of adult healthy male camels were obtained from El Qurain abattoir in Sharkia. The eyelids and their adnexa were carefully examined and dissected to display and photographe the MGs. The palpebra tertia surface of the MGs was photographed by the stereo-microscope.

\section{For light microscopy}

Specimens were fixed in $10 \%$ buffered neutral formalin, and submitted for histological processing, including stains with $\mathrm{H} \& \mathrm{E}$, Alcian blue (Ab) (2.5), Weigert s stains, Silver technique (32) and Crossmon's trichrome stain (33).

\section{For electron microscopy}

Samples of $1 \mathrm{~mm}^{3}$ thick were fixed in $2.5 \%$ glutaraldehyde in phosphate buffer. After hours the tissues were washed thoroughly in the buffer, postfixed in $1 \%$ osmium tetroxide, rinsing with buffer then, dehydrated in ascending grades of ethanol ending with propylene oxide, and embedded in Epoxy resin. Semithin sections were cut on a MT2 Sorvall microtome and stained with toluidine blue. Ultrathin sections were cut on a RMC MT6000$\mathrm{XL}$ ultramicrotome, mounted on copper grids and stained with uranyl acetate and lead citrate. The ready ultrathin sections were examined and photographed at electron Microscope Research Laboratory (EMRL), Faculty of Science, Ain Shams University by a JOEL electron microscope(JEM 1200 EX II) (34).

\section{RESULTS}

Macroscopically

The MG was an extrapalpebral welldeveloped flattened sheet structure that located in the inferior aspect of the eye. It occupied the 
area between the eyelids and third eyelid. It had two attached ends; one with third eyelids fascia and the other end was embedded in the nasal side of both upper and lower eyelids toward the medial commissures (Fig.1). It had two surfaces; the smooth whitish palpebral and the irregular slightly greyish palpebra tertia surfaces. The latter surface showed dark melanin pigments mainly towards the both attached ends, several ductal orifices, and associated fine hairs (Fig.2).

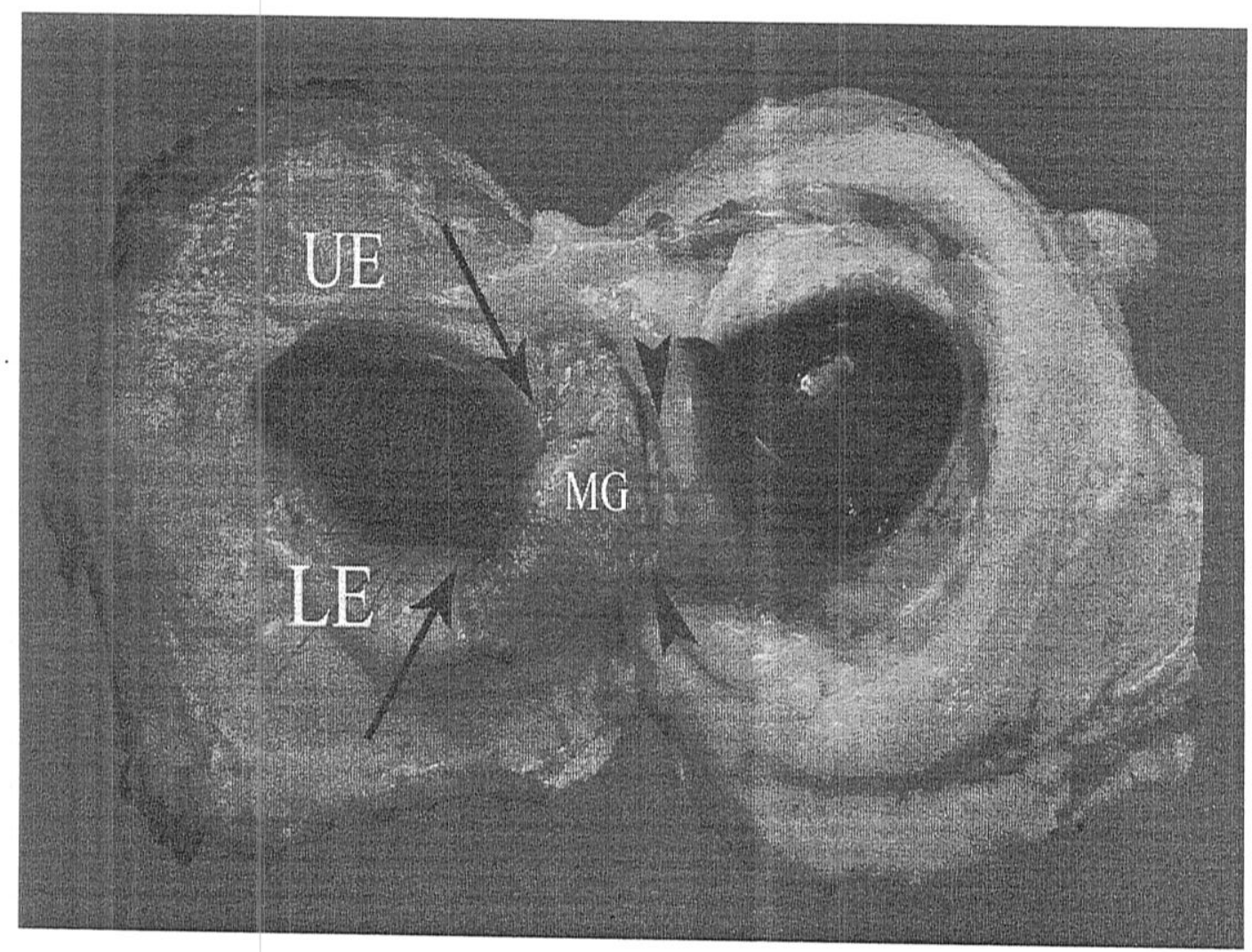

Fig.1. A photograph of back view of dissecting flap of upper "UE" and lower "LE" eyelids to illustrate the meibomian gland "MG".It appeared attached between the nasal side of the eyelids "arrow" and the third eyelid"arrowhead". 


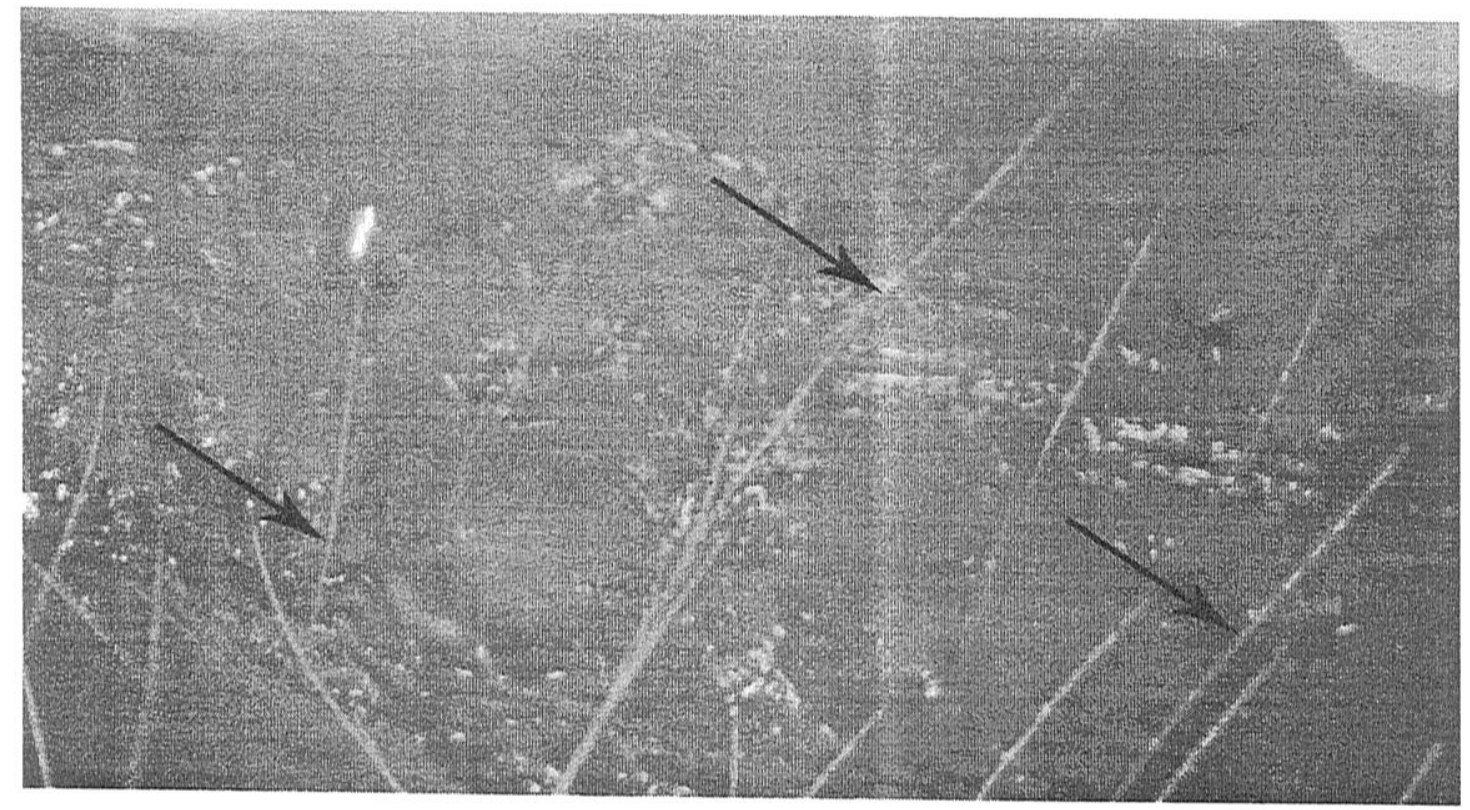

Fig.2. A photograph of the MG palpebra tertia surface showing the associated fine hairs "black arrows".

\section{Light microscopic examination}

Examination of the MG sections showed that, it was consisted of epithelial elements supported by C.T. elements.The epithelial elements were formed of covering (surface) and glandular epithelium. The latter was large simple branched multilobular acinar glands (Fig. 3). The proximal end of single main duct opened onto the palpebra tertia surface and had numerous fine folds that were arranged concentrically around the orifices. While,the disital end was branched into many ductules towards the saccular acini.. The proximal end of the main duct was lined with stratified cuboidal epithelium with obvious melanin pigments at the basal cell layer (Fig.4A) and stratified squamous epithelium toward the disital end (Fig.4B) .The ductules that directly connected to acinar glands were lined with flat bilayer cells (Fig.4C). Each lobule was clusters of saccular (alveolar) acini .The latter appeared honeycomb-like and lined with four types of cell layers. These cells arranged from basement membrane to the lumen;basal cells with flat nuclei, moderately differentiated meibocytes of polygonal in shape with large discoid basophilic nuclei and eosinophilic cytoplasm , well- differentiated meibocytes of polygonal in shape with slightly basophilic nuclei and pale cytoplasm, the degenerated meibocytes with pyknotic and fragmented nuclei surrounded by pale cytoplasm. The acidophilic secretions were found adjacent to the acinar lumen. The cell boundaries of moderately, well- differentiated and degenerated meibocytes were clear (Fig.5).The acini of MGs were negatively reacted with both PAS (Fig.6A) and $\mathrm{Ab}$ (Fig.6B).The interlobular hair follicles were detected (Fig.3, 7) and formed from outside to inside; the C.T. sheath of mainly collagenic fibers, glassy membrane that reacted to $\mathrm{Ab}$ (Fig.6B), external and internal root sheath that reacted to PAS (Fig.6A). The covering epithelium was covered only the palpebra tertia surface and formed of stratified cuboidal epithelium with many goblet cells (Fig.8A).The latter was reacted positively with both PAS (Fig.8B) and Ab (Fig.8C). The C.T. elements were found under the covering epithelium and around the glandular epithelium (Fig. 3).The C.T. elements composed primarily of closely packed bundles of collagen fibers (Fig. 9) .The reticular fibers were restricted around the glandular acini (Fig. 10). Very fine dispersed elastic fibers observed especially towards the palpebral surface. Examination of semithin sections showed nuclei of fibroblasts as well as large numbers of oval to fusiform mast cells were noticed in C.T. around acini (Fig. 11). 


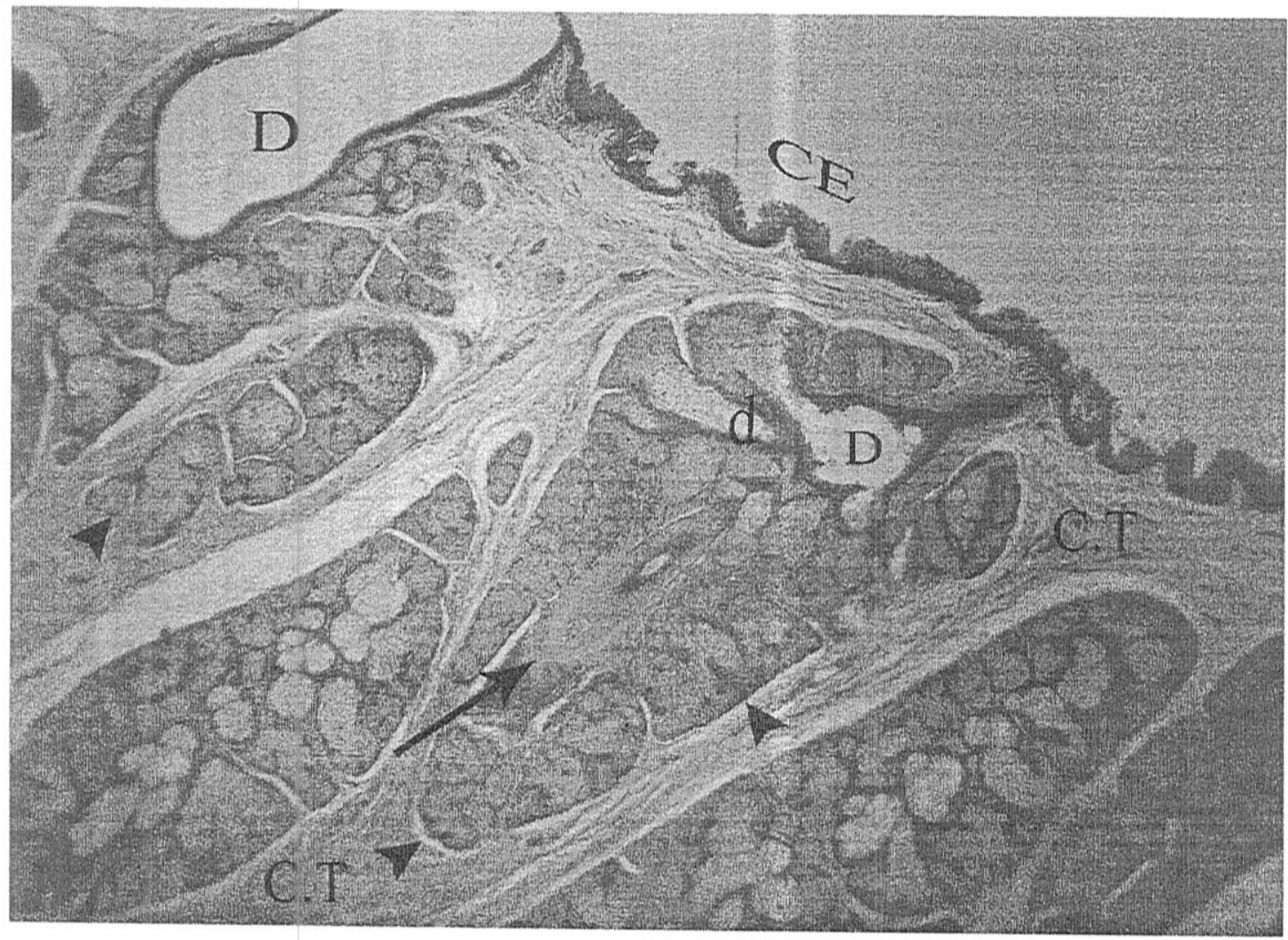

Fig.3.A photomicrograph of meibomian gland section showing covering epithelium"CE", multiple lobules"arrowheads" are connected by means of short ductules "d" to the terminal end of single main duct "D". Hair follicles "arrows" are seen inbetween the lobule. The connective tissue"C.T." are surrounded the lobules.

Stain : H\& E Obj. $x 4$ : Oc.x10

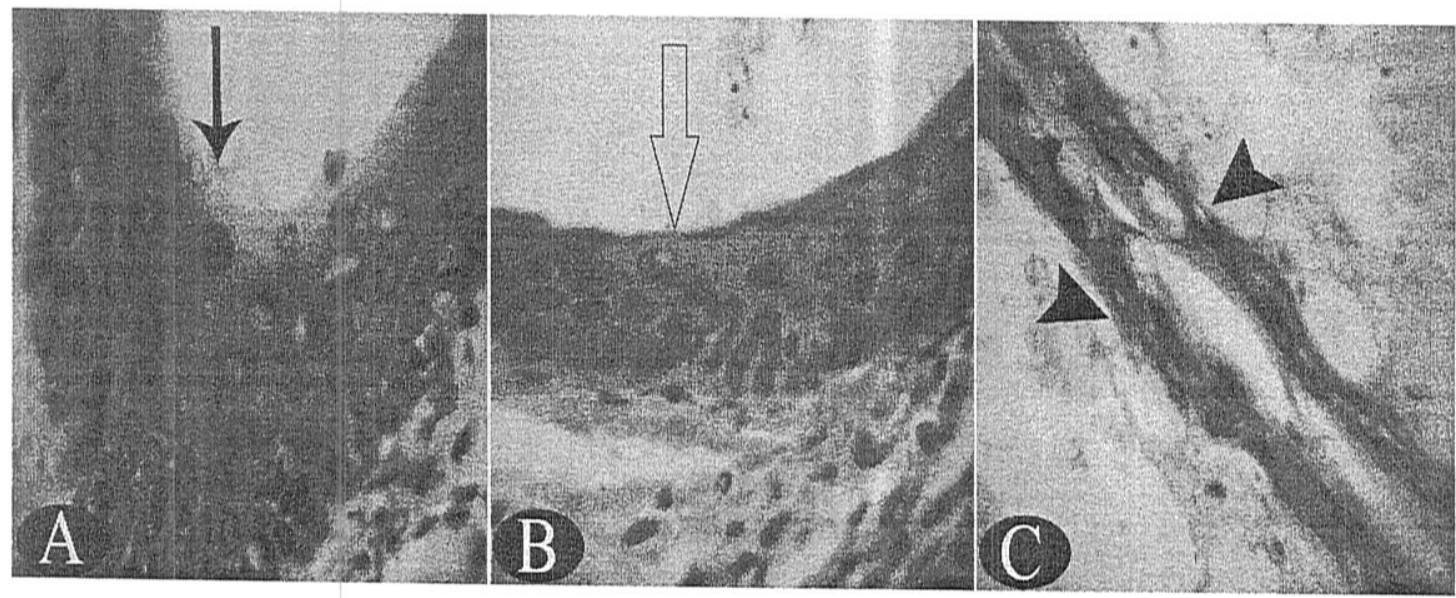

Fig.4.A higher magnification of the previous image showing(A) stratified cuboidal epithelium "arrow" of the main duct proximal end , ( B) stratified squamous epithelium "open arrow"of main duct disital end, (C) flat bilayer cells "arrowheads" of the ductules.

Stain : H\& E Obj. x100 : Oc.x10 


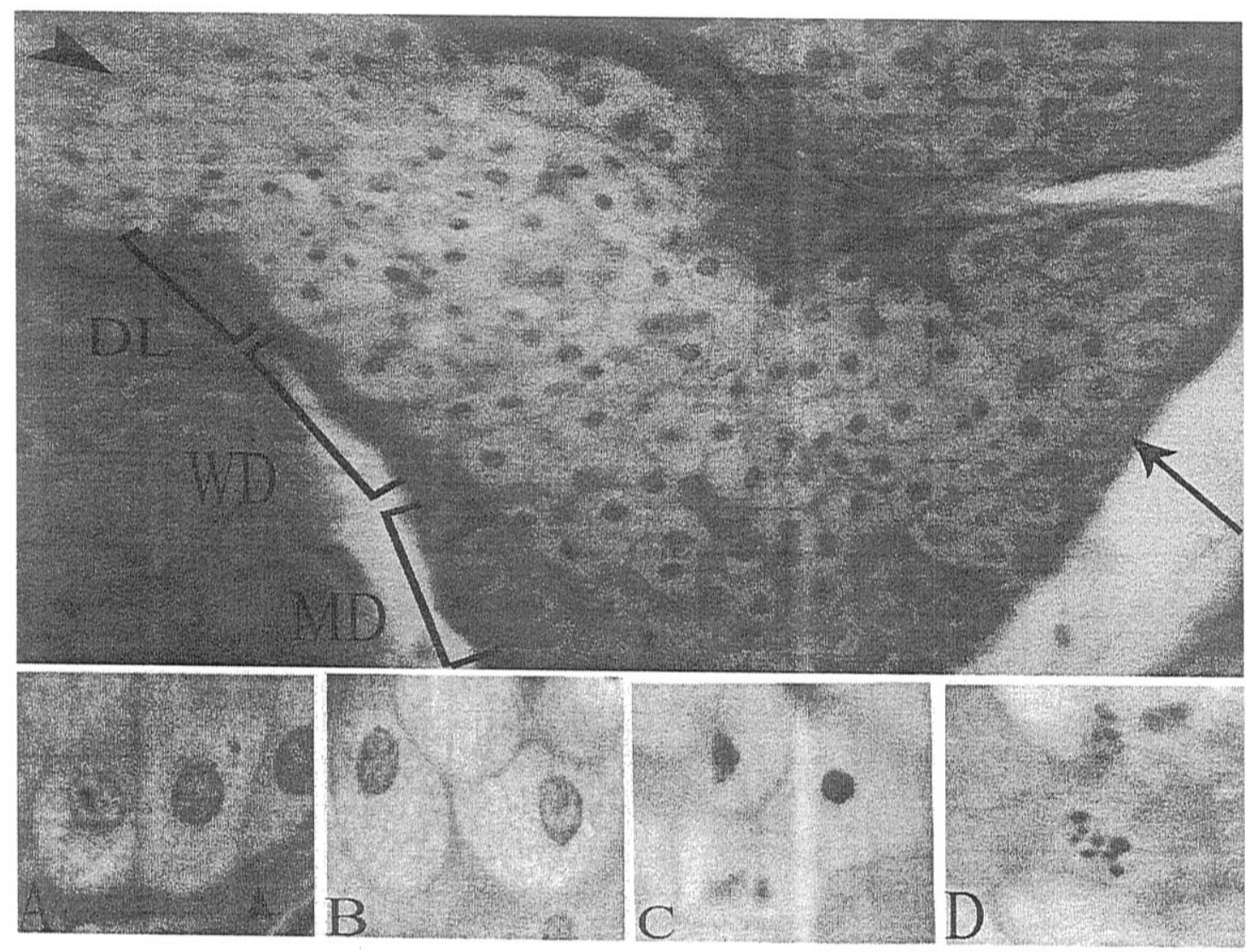

Fig.5. A higher magnification of (Fig.3) showing acini is lined with basal cell layer "arrow", moderately differentiated "MD",well-differentiated" WD" and degenerated cell layers "DL".Note acidophilic secretion"arrowhead" adjacent to the acinar lumen.

Stain : H\& E Obj. x40: Oc.x10

Inset of meibocytes in various differentiated stage; (A) basal cell" arrowhead" and moderately differentiated meibocytes, (B) well-differentiated meibocytes ,(C,D) Degenerated meibocytes with pyknotic (C) then fragmented nuclei (D).

Stain: H\& E Obj. x100 : Oc.x10 


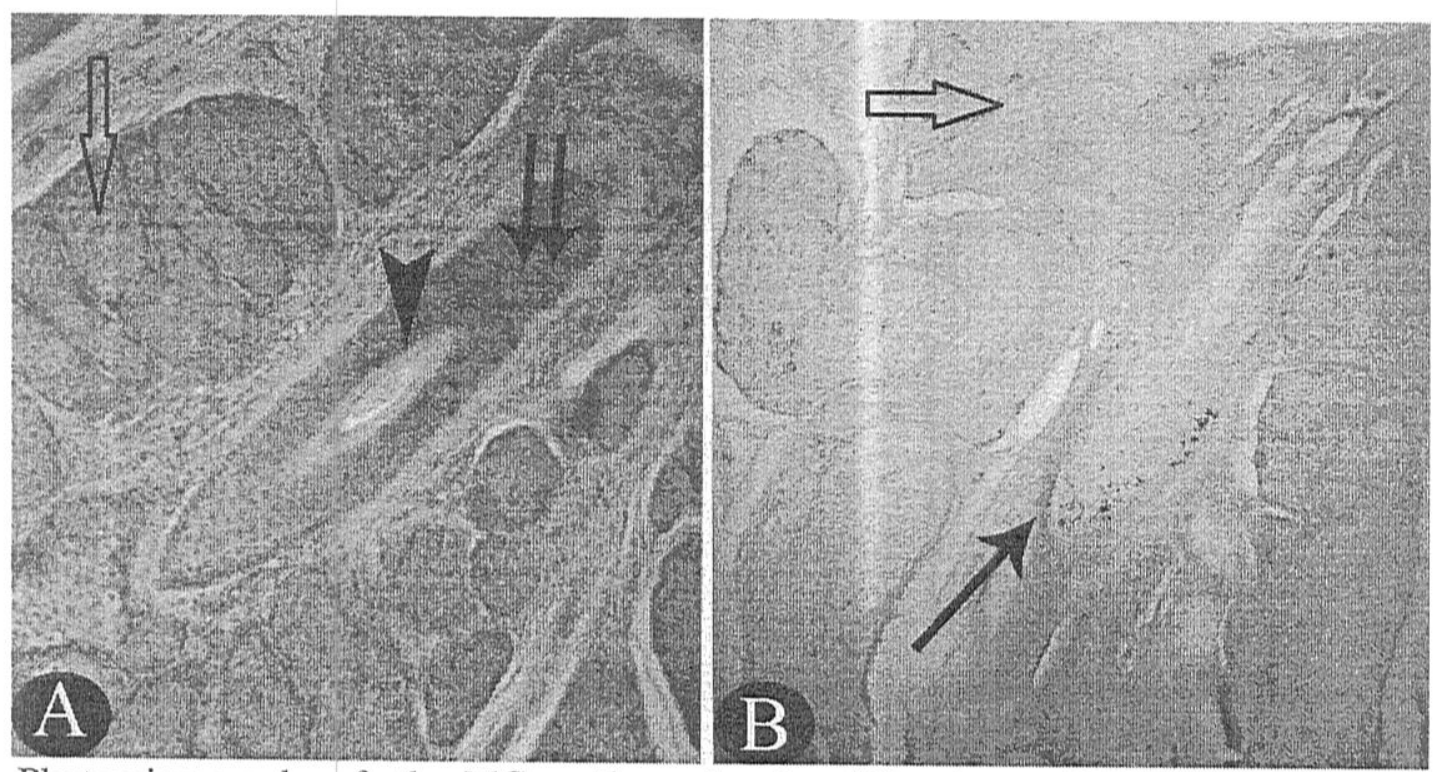

Fig.6. Photomicrographs of the MG sections showing (A) acinar cells are negatively reacted to PAS "open arrow" and positive in external"double arrow" and internal"arrowhead" root sheath of hair follicle.(B) acinar cells are negatively reacted to Ab "open arrow" and positive in the glassy membrane "arrow" of hair follicle.

Stain: (A) PAS (B) AB Obj. x10: Oc.x10

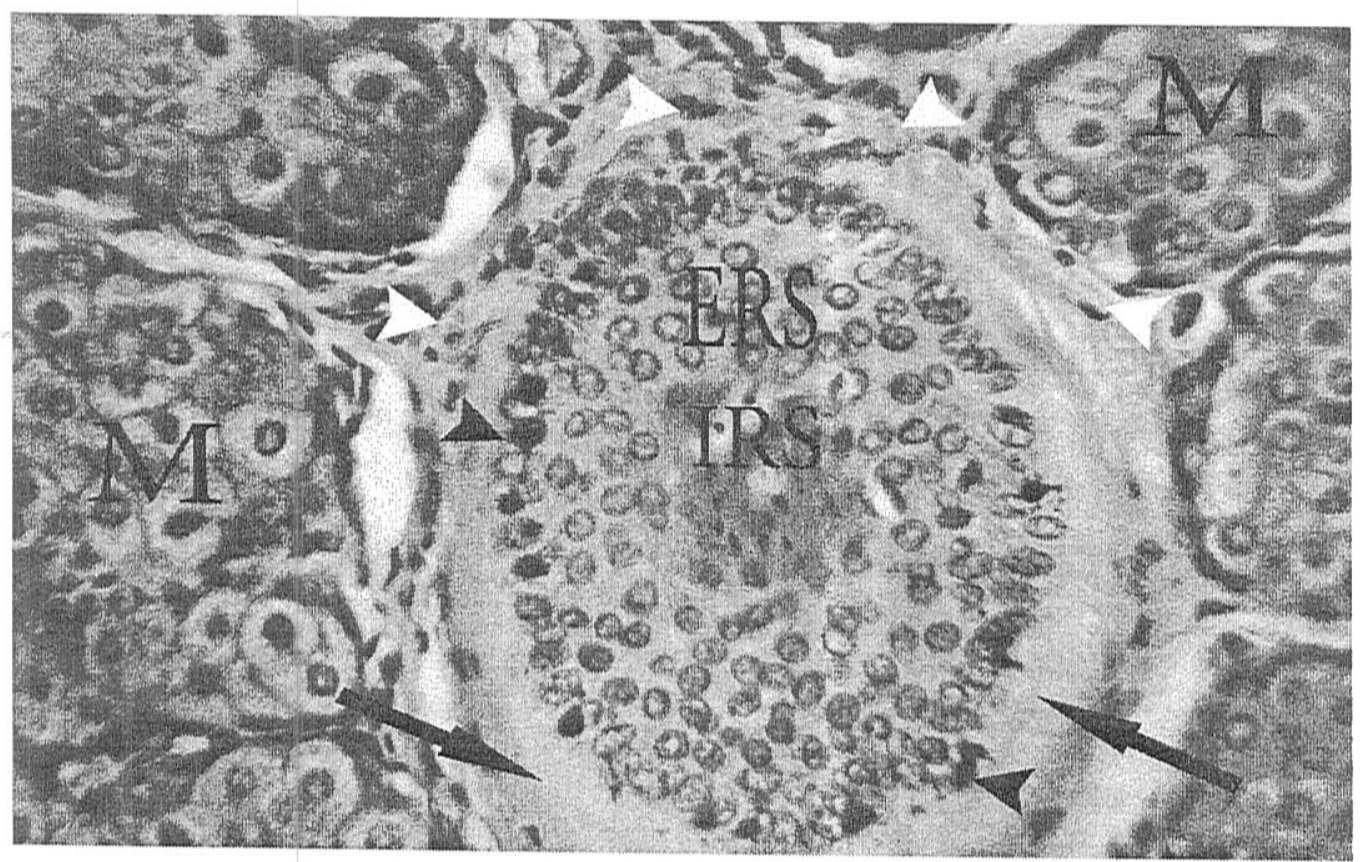

Fig.7. A photomicrograph of the MG section showing transverse section of hair follicle formed of C.T. sheath "white arrowheads", melanin pigment "black arrowheads", glassy membrane"black arrows", external "ERS" and internal"IRS" root sheaths. Note meibocytes "M"of surrounded acini.

Stain : H\& E

Obj. $\mathrm{x} 40$ : Oc. $\mathrm{x} 10$ 

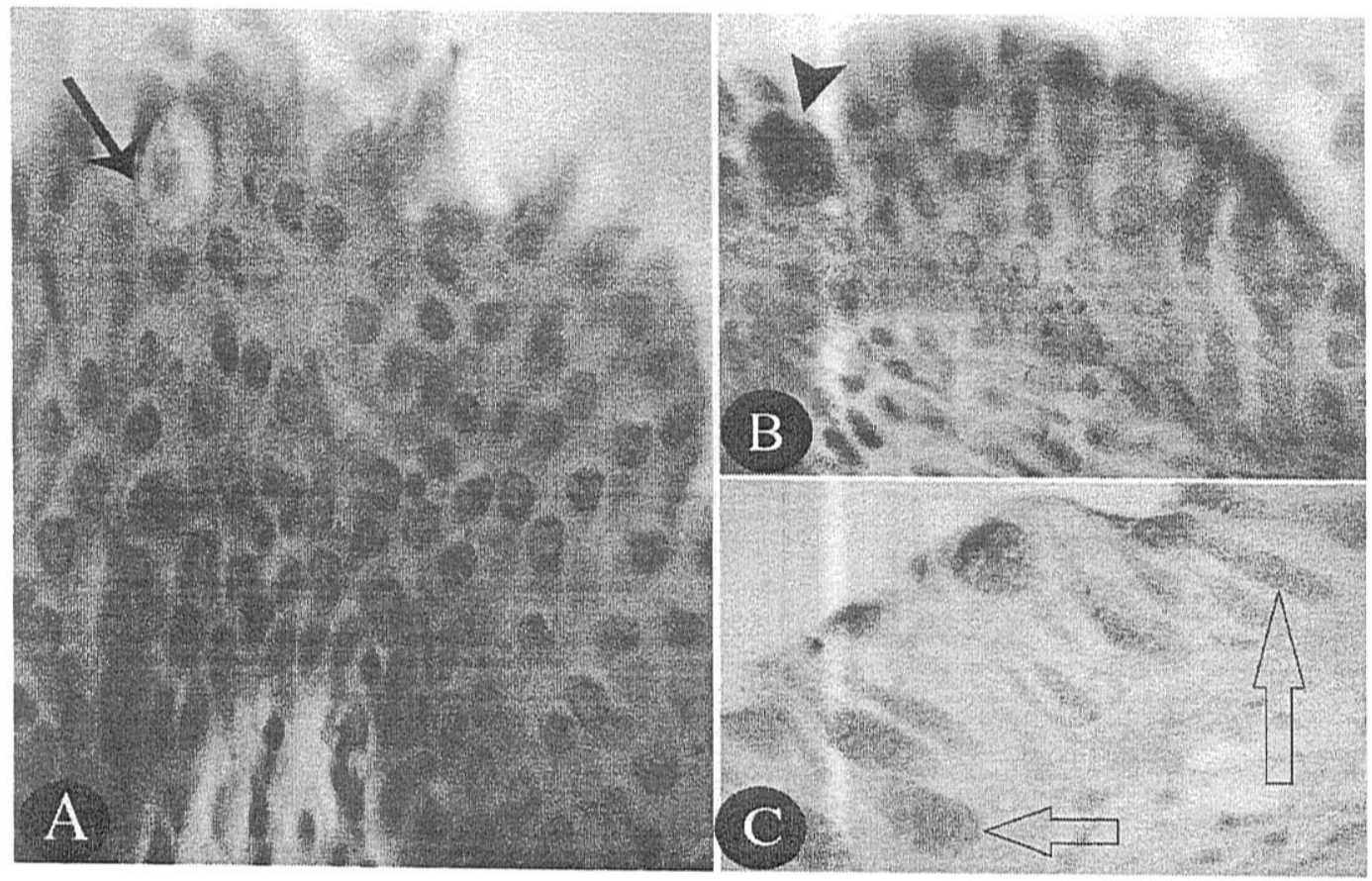

Fig.8. Photomicrographs of the covering epithelium revealing the (A) stratified cuboidal epithelium with goblet cells"arrow". (B) The goblet cells positively reacted with PAS "arrowhead" and (C) Ab "open arrow".

Stain : (A):H\& E (B):PAS (C):Ab Obj. x100 : Oc.x10

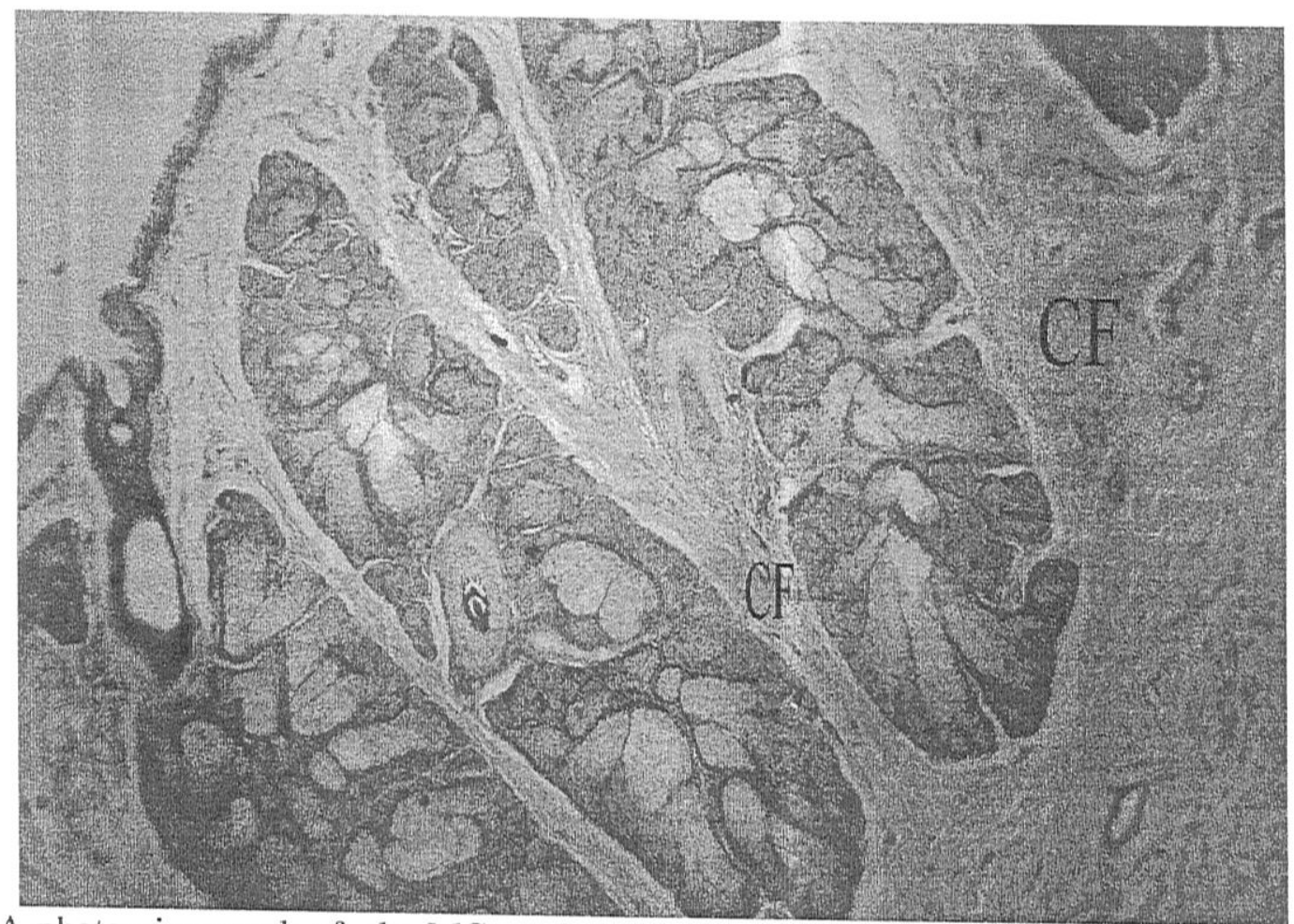

Fig.9. A photomicrograph of the MG section showing collagenic fibers "CF" distribution around the multilobular glands.

Stain : Crossmon's trichrome Obj. x4 : Oc.x10 


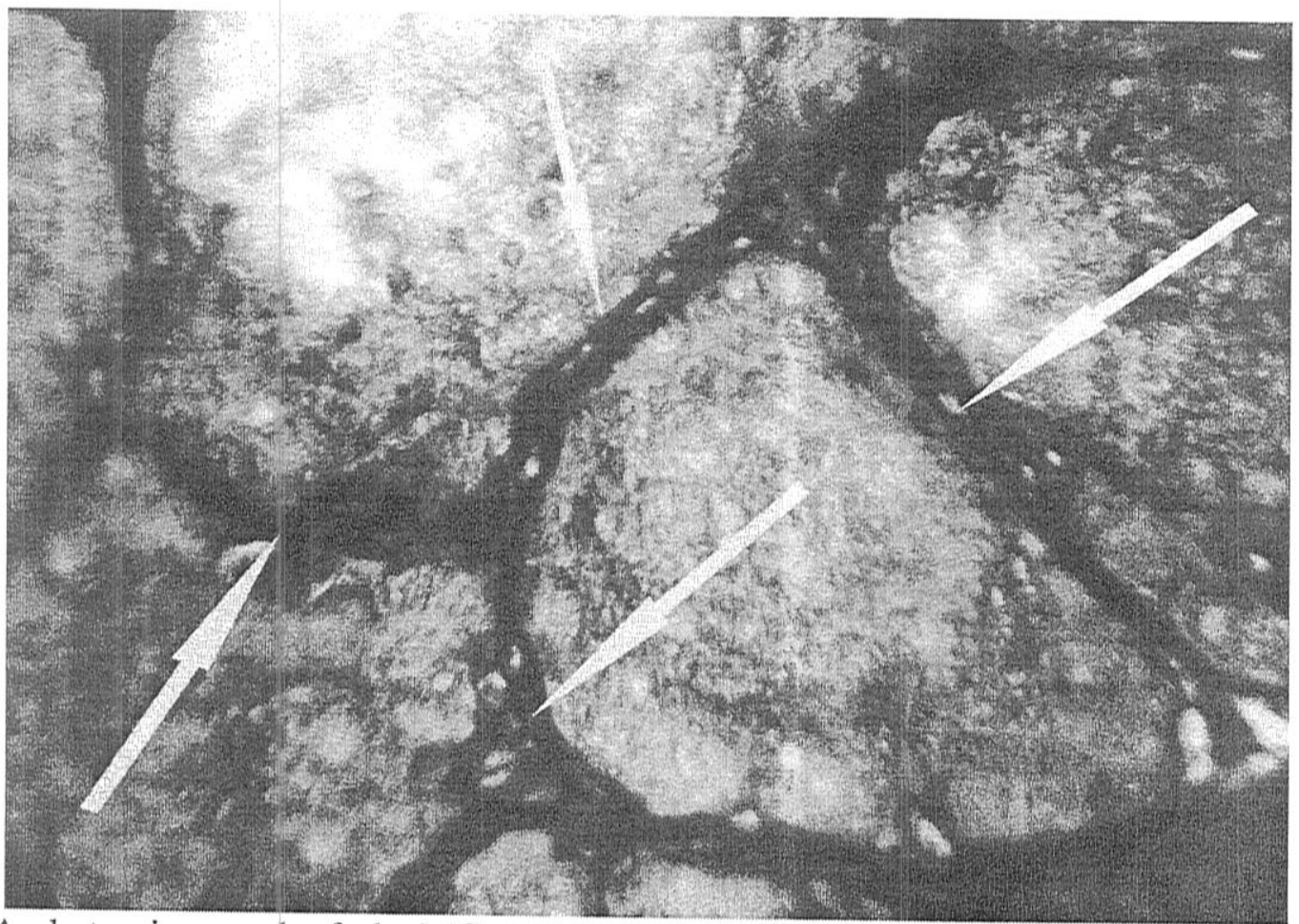

Fig.10. A photomicrograph of the MG section showing reticular fibers" white arrow"surround the glandular acini.

Stain :Silver impregnation technique . Obj. x100 : Oc.x10

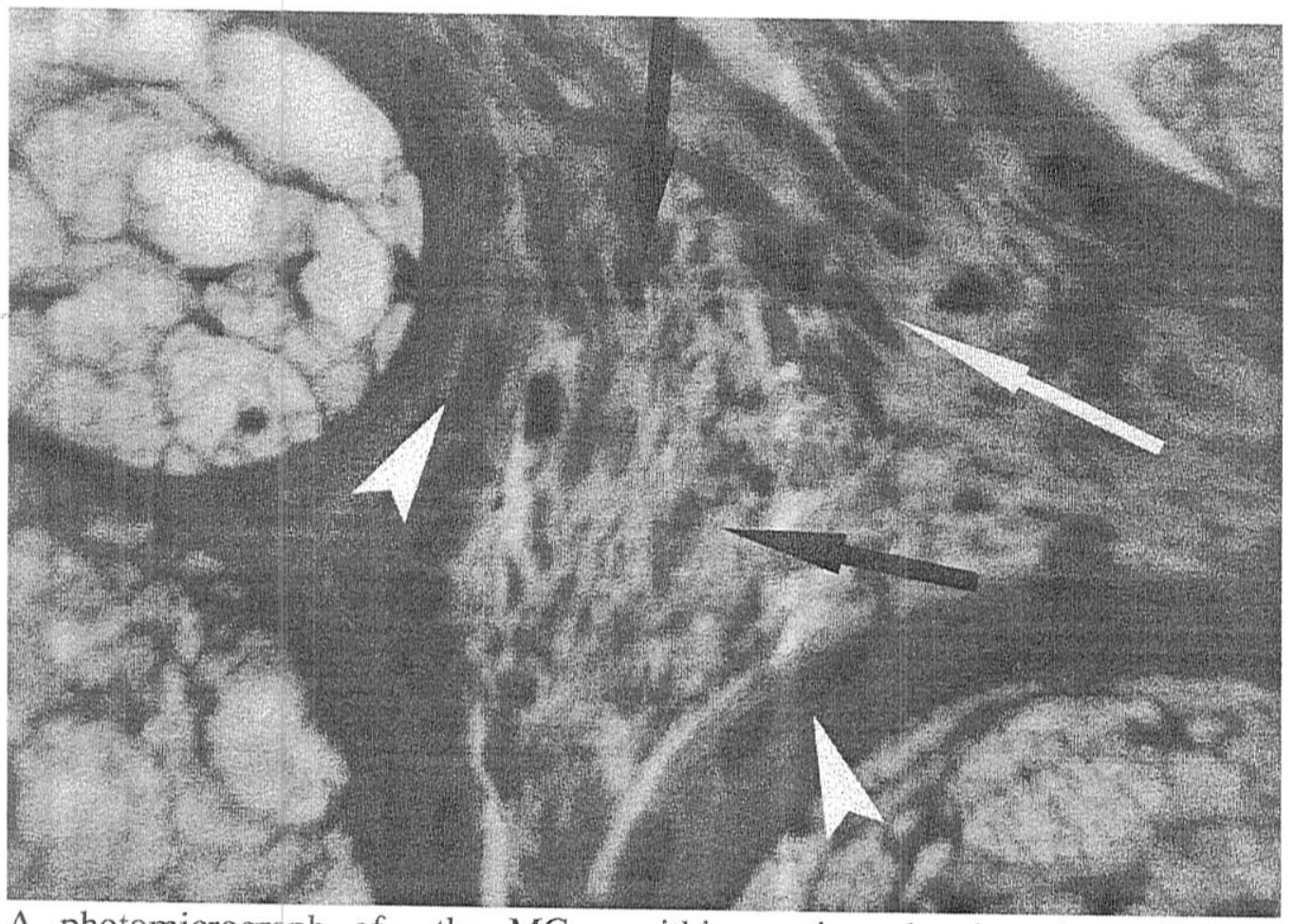

Fig.11. A photomicrograph of the MG semithin section showing the mast cells"black arrow",fibroblast cell "white arrow" and basal cells" white arrowhead".

Stain : Toluidine blue Obj. x100 : Oc.x10 


\section{Electron microscopic examination}

Examination of utrathin sections revealed four types of glandular lining cells : basal cells , moderately differentiated, well- differentiated and degenerated meibocytes.The basal cells were resting on basement membrane by many hemidesmosomes and connected with the differentiating cells by interdigitations. They were flattened electron dark and contained elongated central nuclei with irregularly clustered chromatin (Fig.12). The moderately differentiated meibocytes were observed inbetween basal cells and well-differentiated meibocytes (Fig.12). They had ovoid to nearly rounded nuclei with islets of heterochromatins.In their cytoplasm,many electron dense mitochondria and moderate number of different sized SVs were appeared intermingled (Fig.13A). Two forms of SER : a grid lattice and parallel cisternae commonly associated with SVs were detected. Both the
Golgi complex and rough endoplasmic reticulum (rER) were hardly seen (Fig.13B). Closely interdigitations were seen between the moderately differentiated meibocytes and neighboring cells of well- differentiated meibocytes (Fig.12).The well- differentiated meibocyte had central round electron pale nucleus that partially indented from one side by SVs. The latter was numerous, varied in size and surrounded by a disorganized cytoplasm in which many small dense bodies of lysosomes were prominent (Fig.14A). The degenerated meibocyte had irregular outline nucleus that completely indented with SVs.The latter was markedly increase in size, number and fused with each other.lysosome were observed in the obvious disorganized cytoplasm(Fig.14B). A sparse melanocytes with electron dense membrane-bounded granules were extended into the interstices between meibocytes were noticed (Fig.15). 


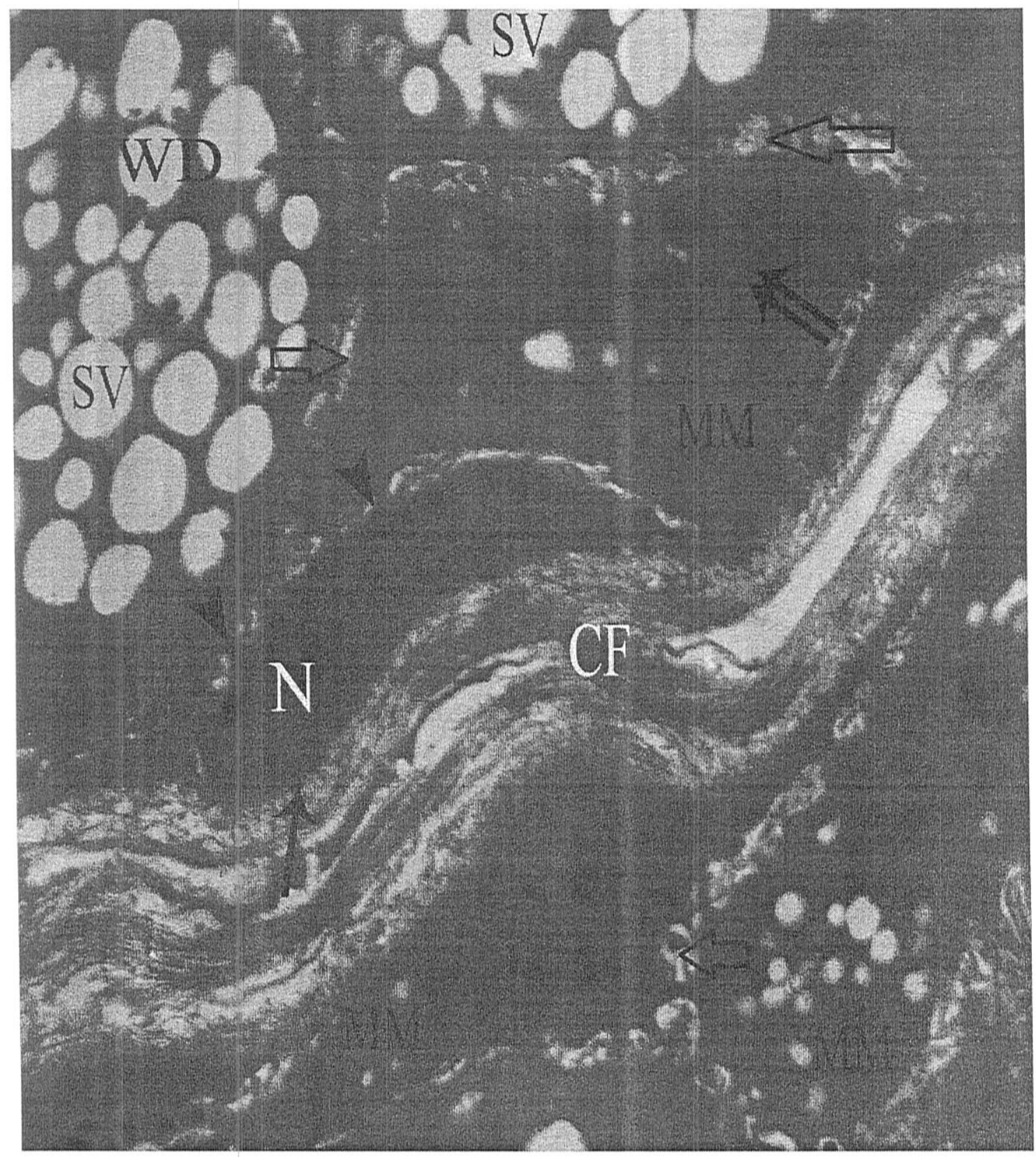

Fig.12. An electron micrograph showing three types of meibocytes; basal cell with elongated central nucleus "N" and is resting on basement membrane by many hemidesmosomes "arrow" and connected with the differentiating cells by interdigitations "arrowheads. The moderately differentiated meibocytes "MM" with many electron dense mitochondria "double arrows".The well-differentiated meibocytes "WM" with many secretory vesicles "SV". Closely interdigitations are seen between the moderately and well-differentiated meibocytes "open arrows". Note collagen fibers"CF" inbetween acini..

Print Mag. X 8100 : Direct Mag.x 1500 


\section{Balah et al.,}

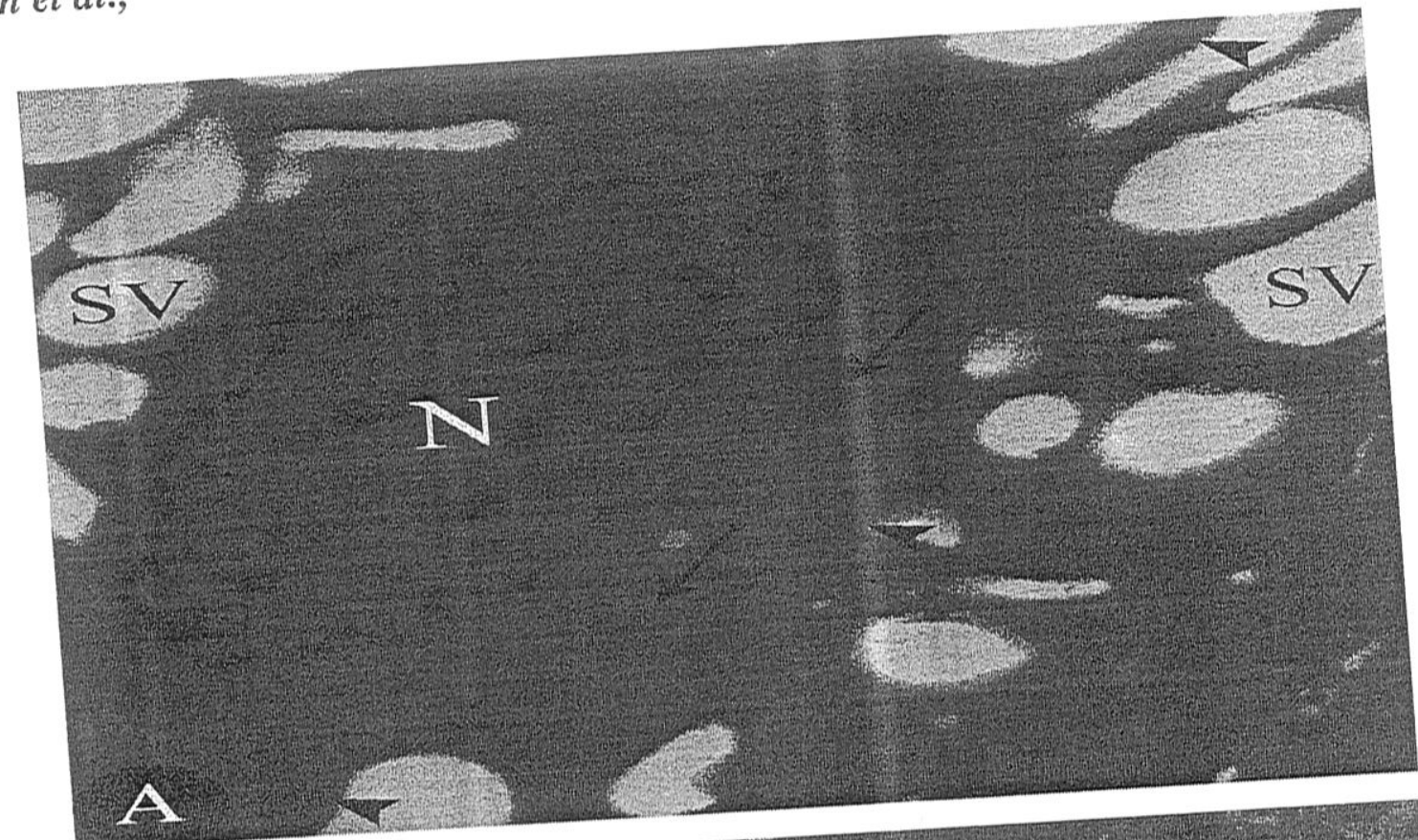

A
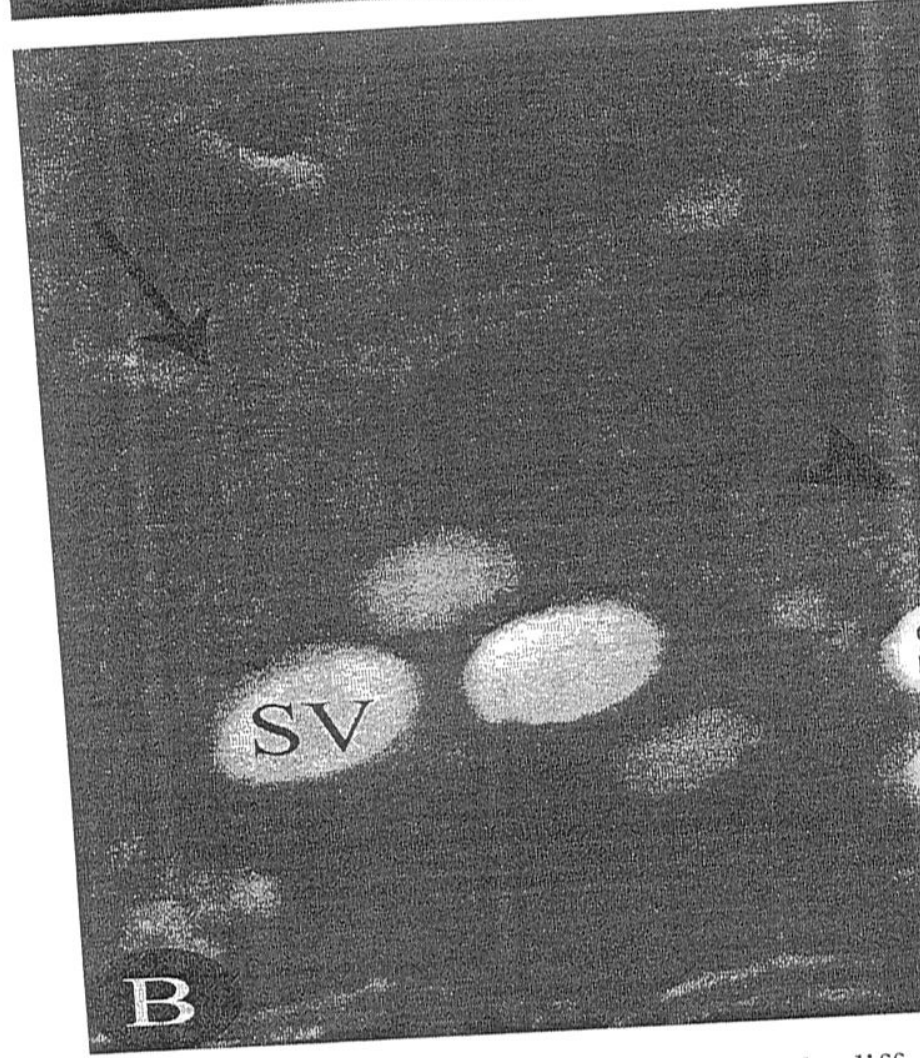

Fig. 13. An electron micrographs of the moderately differentiated meibocyte showing (A) ovoid nucleus "N", many electron dense mitochondria"arrows" and moderate number of different sized secretory vesicles "SV" .some secretory vesicles intermingled with mitochondria "arrowheads". (B) Two forms of smooth endoplasmic reticulum : a gric lattice "arrowhead" and parallel cisternae "arrow" commonly associated witł secretory vesicles "SV" were seen.

(A) Print Mag. X 16200 : Direct Mag.x 3000

(B) Print Mag. X 32400 : Direct Mag.X 6000 

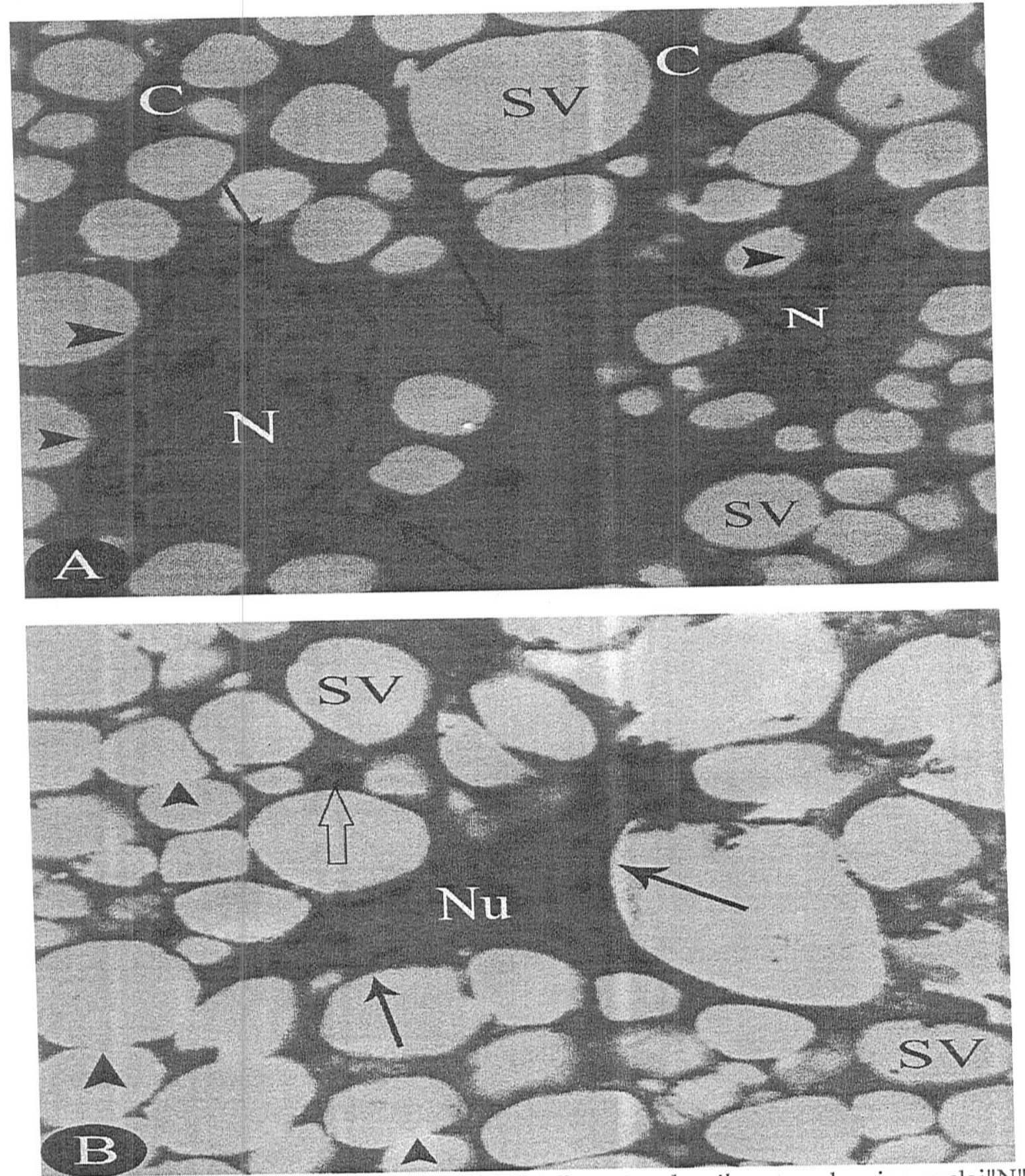

Fig.14. An electron micrographs of (A) two well-differentiated meibocytes showing nuclei" $\mathrm{N}$ " are partially indented by secretory vesicles "arrowheads". The secretory vesicles "SV"are numerous , varied in size and surrounded by a disorganized cytoplasm" $\mathrm{C}$ " that housing prominent lysosomes"arrows".(B) Degenerated meibocytes showing nucleus "Nu" are completely indented with multiple secretory vesicles" arrows".The secretory vesicles"SV" are completely filled the cytoplasm"C" and fused with each other"arrowheads".Lysosome is observed"open arrow". Print Mag. X 10800 : Direct Mag.x 2000 


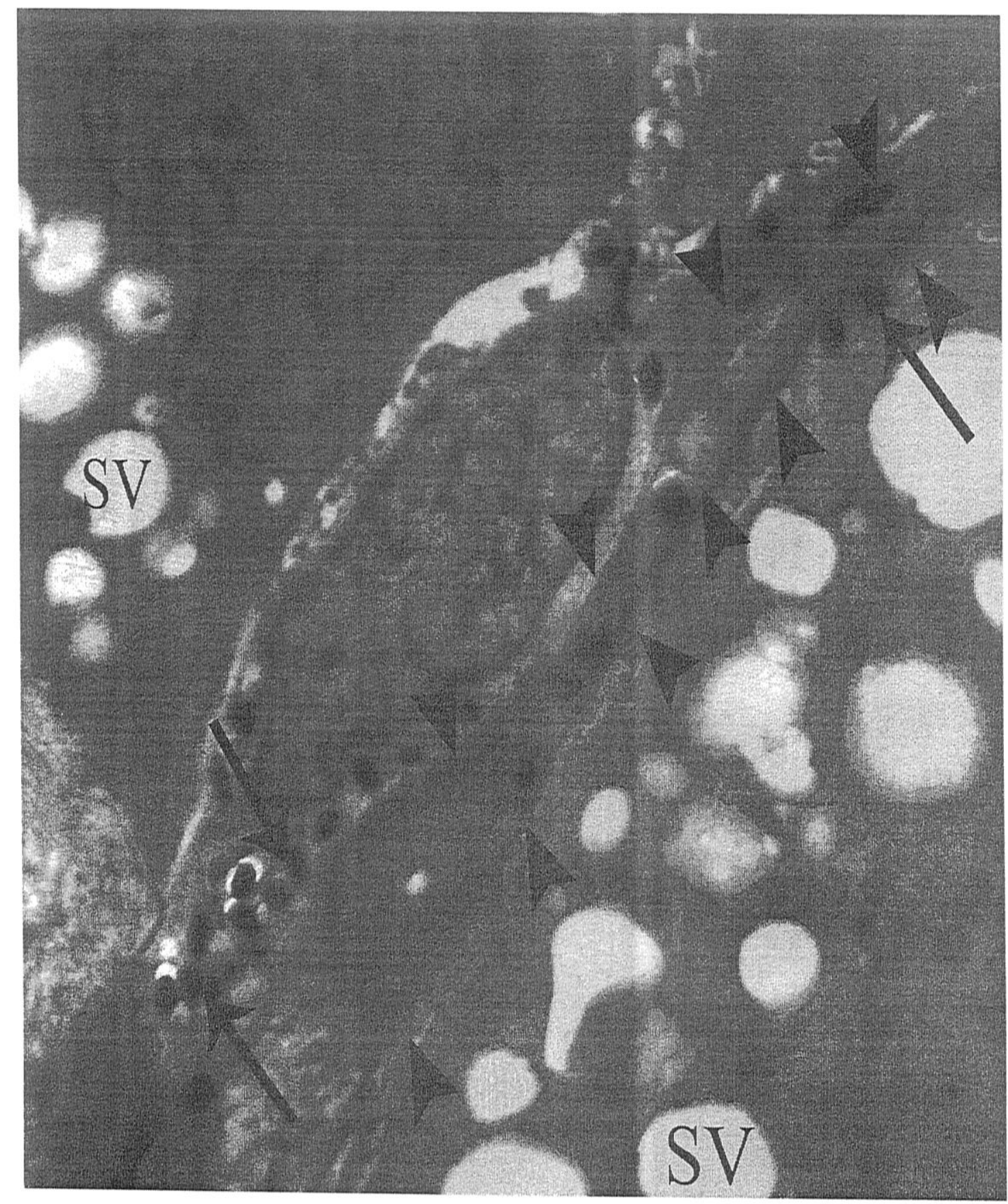

Fig.15. An electron micrograph of the interstices between meibocytes showing the melanin granules "arrows" and melanocyte processe"arrowheads" .The secretory vesicles "SV" of meibocytes were seen.

Print Mag. X 13500 : Direct Mag.x 2500 


\section{DISCUSSION}

In mature male camel, morphology and position of the MG was different from other animals. The position variations of the $\mathrm{MG}$ were thought to be desirable in order to life nature of the camel (environmental desert habits). An apparent discrepancy between our results of the MG as it was an extrapalpebral well-developed flattened sheet structure that located in the inferior aspect of the eye and it has been reported absence of MGs in camel (14-16) . It is well known that, the MGs extend equally along the entire length of both eyelids with visible orifices in the lid margin as described in voles and lemmings (13), rats $(7,35)$,primates , steer, rabbit, and human (2) ,bats (18) and guinea pigs (9). In chinchillas, it was temporal broadened glandular complex (10) and in some subfamilies of microtinae and lemmings have only a few glands in the lid, supplemented by other extraorbital glands delivering their secretion at the temporal canthus (13).

The investigated MG was associated with the fine hair. Results are differ from that reported in Egyptian Water Buffalo (36) and human (37) where MG are not associated with hair follicles and are embedded within the tarsal plate of both eyelids. We depicted the presence of hair to remove and prevent dust particles from entering the palpebra tertia surface that contained opening of ducts to avoid their closure .

The present study revealed that the MGs of the camels were simple branched acinar glands and were surrounded within dense collagenous C.T. These features were in agreement with several investigations (6) in rabbits, cats, goats, sheep and cattle; (7) in adult male albino rat; (18) in bats and in human (5, $19,20)$.

The examined MGs were characterized by a single main duct. The disital end of the duct branched into multiple ductules connecting to alveolar acini. These findings are endorsed by the described results in steer (2), and mouse (8). On the contrary, acini were connected by means of short ductules along the length of the main duct, as in the primate $(2)$, rabbit $(2,38)$ and human $(5,2,19,29)$.

Regarding the mode of camel MGs secretion and presence of four types of cells lining its MGs: basal cells, moderately differentiated, well- differentiated and degenerated meibocytes suggesting that the MG in camel was a holocrine gland, in which the cell ruptures and both the cell and its contents are released. This results was similar to that obtained in human $(3,39,40)$. The acidophilic secretions were found adjacent to the acinar lumen in the current work. These data was interpreted in rat (17), rabbit and primate (2) as degenerating brusting cells.

The ultrastructure of examined MG acinar cells was varied.The basal cells were flattened and contained elongated central nuclei and their cytoplasm was devoid of SVs. These results are similar to the findings in human (39). However, it has been reported that the lipid vesicles are occasionally seen in these cells of rat (17). In the rabbit and primate (2) and human (39) added that the basal cell cytoplasm is scanty and contains a large number of free ribosomes, mitochondria, tonofilaments, scarce rER and small Golgi apparatus. The basal cells were resting on basement membrane by many hemidesmosomes and connected with the differentiating cells by interdigitation. These results were partially similar to that reported in rabbit, primate (2) and human (40) where the desmosomes linking basal stem cells to the differentiating cells.

The saturated fatty acids do not react with osmium tetroxide and so they may washed out by solvents used in dehydration and embedding (41).These data were interpret the appearance and contents of the SVs in the examined MGs.

This study cleared a close interdependence between SVs, mitochondria and sER. These results were partially in accord with that (40) which showed that the cells initiate their differentiation, the sER and the Golgi apparatus become prominent. The moderately differentiated meibocytes of this study showed ovoid to nearly rounded nuclei, many electron dense mitochondria and 
moderate number of different sized SVs appeared in their cytoplasm. The same results were described in human (40). The sER was prominent and had various forms include grid lattice and parallel cisternae. The SVs varied greatly in size and number between different maturing meibocytes and within the same meibocyte. Some of these SVs fused with each other, others were intermingled with the mitochondria and they appeared to indent the nucleus.These results were mostly as those mentioned in the camel sebaceous glands in the skin (42).

The lysosomes were prominent in welldifferentiated meibocytes and few in degenerated meibocytes. These results were mostly similar to those mentioned in sebaceous gland of subhuman primates (43).It has been suggested that lysosomes are involved in the autolytic phase of holocrine secretion (44).

We could suggest that in this desert animal the melanocytes by their melanin pigment, may play a key role in the protection of the MGs from solar radiations, a similar function for the melanocytes was stated (37).

\section{REFERENCES}

1. Tiffany J M (1995): Physiological functions of the meibomian glands. Prog. Retinal Eye Res., 14:47-74.

\section{Jester $J V$, Nicolaides $N$ and Smith $R E$} (1981):Meibomian gland studies: histologic and ultrastructural investigations. Invest. Ophthalmol. Vis. Sci.20(4): 537-547.

\section{Bron A $J$, Benjamin $L$ and Snibson $G R$} (1991): Meibomian gland: disease classification and grading of lid changes. Eye. 5:395-411.

4.Byun TH, Kim JT, Park $H W$ and Kim $W \quad K$ (2011): Timetable for Upper Eyelid
Development in Staged Human Embryos and Fetuses. Anat. Rec. 294:789-796.

5.Black $E H$, Nesi $F A$, Gladstone $G J$ and Levine M R (2012): Smith and Nesi's Ophthalmic Plastic and Reconstructive Surgery"Anatomy of the Ocular Adnexa Orbit and Related Facial Structures. Springer New York Dordrecht Heidelberg London $3^{\text {rd }}$ Ed Section 1. Pp 3-58.

\section{Ibrahim I A, Kelany A $M$ and Taha $M$} (1992):Comparative anatomical and histological studies on the meibomian (tarsal) glands in rabbits cats goats sheep and cattle. Assiut Vet. Med.J. 28(55):81-92.

7.El-Bakary N A (2010): Histological Histochemical and Immunohistochemical Study on the Structure of Meibomian Gland of Adult Male Albino Rat. Egypt. J. HistoL $.33(1): 1-7$.

8Jester $J V$, Rqjagopalaat $S$ and Rodriguesf $M$ (1988): Meibomian Gland Changes in the Rhino $\left(\mathrm{hr}^{\mathrm{rh}} \mathrm{hr}^{\mathrm{rh}}\right)$ Mouse. Investi. Ophthalmol. \& Visual Sci.29(7): 1190-1194.

9.Gasser $K$, Fuchs-Baumgartinger A, Tichy A, and Nell $B$ (2011): Investigations on the conjunctival goblet cells and on the characteristics of glands associated with the eye in the guinea pig. Vet. Ophthalmo., 14 1:26-40.

10.Voigt $S$, Fuchs-Baumgartinger A, Egerbacher $M$, Tichy $A$ and Nell $B$ (2012): Investigations on the conjunctival goblet cells and the characteristics of the glands associated with the eye in chinchillas(Chinchilla Laniger). Vet. Ophthalmol.15(5): 333-344.

11.Davis $R K$, Doane $M G$, Knop E, Knop $N$, Dubielzig $R R$, Colitz $C M H$, Argüeso $P$ and Sullivan $D$ A (2012): Characterization of ocular gland morphology and tear composition of pinnipeds. Vet.Ophthalmol. :1-7.

12.Rieppel $O$ (2000): Turtles as diapsid reptiles. Zool. Scripta.29:199-- 212. 
13. Quay W B (1954):The Meibomian Glands of Voles and Lemmings (Microtinae) $1^{\text {st }}$ Ed. Miscellaneous publications Museum of Zoology University of Michigan Press Ann Arbor No.82.

14. Ibrahim MT (1990): Surgical anatomical study on the appendages of the eye in camel buffalo and donkey. Ph.D. Thesis Assiut University.

15.Eidaroos H (1996):Histological and histochemical studies on the upper lower and third eyelids of the one humped camel(Camelus Dromedarius).Acc. in $20^{\text {th }}$ Sci.Conf.Egypt.Soc. Of Histology and cytology.

16.Zayed A E (2004): The prenatal development of the eyelids of the onehumped camel (Camelus dromedarius). Assiut Vet. Med. J. 50: 37-52.

17.Leeson $T S$ (1963): Tarsal (Meibomian) glands of the rat. Brit. J. Ophthal. 47 (10):222-231.

18. Rehorek $S J$, Smith $T D$ and Bhatnagar K P (2010): The Orbitofacial Glands of Bats: An Investigation of the Potential Correlation of Gland Structure with Social Organization. Anat. Record. 293:1433-1448.

19. Williams $P L$, Warwick $R$, Dyson $M$, Bannister LH (1993): Gray's Anatomy. $37^{\text {th }}$ Ed. Ch.7 Pp 1180-1218.Edinburgh Churchill Livingstone.

20.Galloway $N R$, Amoaku W $M K$, Galloway $P H$ and Browning A C(2006): Common Eye Diseases and their Management."Basic Anatomy and Physiology of the Eye". Verlag Pall London $3^{\text {rd }}$ Ed Ch 2 Pp 7-15.

21.Davidson HJ and Kuonen VJ (2004): The tear film and ocular mucins. Vet. Ophthalmol. 7(2): 71-77.

22.Ohashi Y, Dogru M, Tsubota K (2006): Laboratory findings in tear fluid analysis. Clinica. Chimica. Acta. $369: 17$ - 28.
23.Butovich I A (2010): Fatty acid composition of cholesteryl esters of human meibomian gland secretions. Steroids $75: 726-733$.

24. Yuksel H, Gulbahar MY, Aslan L (2005): Congenital synchronous adenomas of meibomian and moll glands of the eyelid in a calf. Vet. Med. Czech 50 (8): 379-383.

25.Perra $M T$, Lanrini $M S$, Serra $A$, Cossu M, Martini $G$ and Sirigu $P$ (1990): Human Meibomian Glands: A histochemical study for androgen metabolic enzymes. Invest. Ophthalmol. \& Vis.Sci. 31( 4):771-775.

26. McCulley J P and Shine W E (2004): The lipid layer of tears dependent on meibomian gland function. Exp. Eye Res. 78:361-365.

27. Butovich I A (2011): Lipidomics of human Meibomian gland secretions: Chemistry biophysics and physiological role of Meibomian lipids.Progress in Lipid Research. $50: 278-301$

28.Linton $R G$, Curnow $D H$ and Riley $W J$ (1961): The meibomian glands: An investigation into the secretion and some aspects of the physiology. Br. J. Ophthalmol. 45:718-723

29.Driver $P J$ and Lemp M A (1996): Meibomian gland dysfunction Surv. Ophthalmol. 40 (5):343-367.

30. Csillag A (2005): Atlas of the sensory organs functional and clinical anatomy. Humana Press Totowa New Jersey Pp 85164.

31. Bron AJ, Tiffany JM, Gouveia SM, Yokoi $N$ and Voon LW (2004): Functional aspects of the tear film lipid layer. Experi. Eye Res. 78 : 347-360.

32.Bancroft $J D$ and Gamble M.(2002): Theory and Practice of histological techniques. 5th ed. Edinburgh Churchil Livingstone New York London. Pp: 165180 .

33.Crossman $G$ (1937): A modification of Mallory's connective tissue stain with a 
discussion of principles involved. Anat.Rec. 69: 33-38.

34.Glauert A M and Lewis $P R$ (1998): Biological Specimen Preparation for Transmission Electron Microscopy. Volume 17 Portland Press London.

35. LeDoux $M S$, Zhou $Q$, Murphy $R B$, Greene $M L$ and Ryan $P$ (2001): Parasympathetic Innervation of the Meibomian Glands in Rats. IOVS 42(11): 2434- 2441.

\section{Sayed-Ahmed A (2009): Prenatal} Development and Micro-Vasculatures of the Eyelids of the Egyptian Water Buffalo (Bubalus buba-lis). J. Vet. Anat. 2 (2):1-21.

37. Junqueira LC Carneiro $J$ and Kelly I (2010): Basic Histology Photoreceptor \& Audioreceptor systems. $11^{\text {th }} \mathrm{Ed} \mathrm{Ch} 23 \mathrm{Pp}$ 456-468. McGraw- Hill Co. Medical publishing Division N. Y. Chicago

38. Jester $J V$, Rife $L$, Nil D, Luttrull $J$ $K$, Wilson $L$ and Smith $R E$ (1982): In vivo biomicroscopy and photography of meibomian glands in a rabbit model of meibomian gland dysfunction. Assoc. for Res. in Vis. and Ophthal. Inc.22(5):660667.

39. Jakobiec $F \quad A$ and Iwamoto $T$ (1982): Ocular anatomy embryology and teratology. "Ocular Adnexa: Introduction to
Lids Conjunctiva and orbit". Philadelphia PA: Harper \& Row. Vol.1 Ch 28 Pp 1-55.

40.Sirigu $P$, Shen $R L$ and Silva $P P$ (1992): Human Meibomian Glands: The infrastructure of Acinar Cells as Viewed by Thin Section and Freeze-Fracture Transmission Electron Microscopies. Invest. Ophthalmol. \& Vis.Sci. 33( 7): 2284-2292

41. Belazi D, Solé-Domènech $S$, Johansson $B$, Schalling $M$ and Sjövall $P$ (2009): Chemical analysis of osmium tetroxide staining in adipose tissue using imaging ToF-SIMS. Histochem. Cell Biol. 132 (1):105-115.

42. Taha A A M (1988): Ultrastructure of the sebaceous glands of the camel (Camelus dromedarius ). J.Anat . $156: 157-168$.

43. Bell M (1971):A comparative study of sebaceous gland ultrastructure in subhuman primates. II. Macaques : Crystalline Inclusions in the Sebaceous Cells of Macaca mulatta M. nemestrina M. speciosa $M$. fascicularis The $\mathrm{j}$. of Cell Biol. 49: 932-936.

44.Brandes D, Bertini $F$ and Smith $E W$ (1965): Role of lysosomes in cellular lytic processes. II. Cell death during holocrine secretion in sebaceous cells. Exp. Mol. Pathol.4:245-265. 
